\title{
Must naive realists be relationalists?
}

\author{
Forthcoming in: European Journal of Philosophy
}

Penultimate draft, 27 April 2019 (corrected)

\author{
Maarten Steenhagen \\ ms2416@cam.ac.uk
}

\begin{abstract}
Relationalism maintains that perceptual experience involves, as part of its nature, a distinctive kind of conscious perceptual relation between a subject of experience and an object of experience. Together with the claim that perceptual experience is presentational, relationalism is widely believed to be a core aspect of the naive realist outlook on perception. This is a mistake. I argue that naive realism about perception can be upheld without a commitment to relationalism.
\end{abstract}

\section{Introduction}

Naive realism is gaining in popularity. In recent discussions about perception, a number of authors have defended a naive realist conception of perceptual experience. The main selling point of naive realism is that it simply regiments a common-sense idea: perception is just the presentation of mindindependent items to us. But what exactly does this amount to? And what does it not?

The standard view, promoted by critics and proponents, is that a naive realist takes a perceptual experience to be a kind of episode or event that is fundamentally both presentational and relational (Campbell 2002; Martin 2006; Nudds 2009; Nanay 2014; French 2018). To claim that perceptual experiences are fundamentally presentational is to claim at least that perceptual experiences are by their very nature constituted, at least in part, by mind-independent objects and their manifest properties. In this way one is able to hold on to the natural idea that perceptual experiences are object-dependent: you can only have a perceptual experience of an object if that object exists. Further, to claim that perceptual experiences are fundamentally relational is to claim that perceptual experiences by their very nature involve a distinctive conscious relation between a conscious subject and some object (Soteriou 2016, p. 10). This relation has been called 'the perceptual relation', or the relation of 'acquaintance' or 'awareness'. According to the standard view, a naive realist must take both object-dependence and mind-dependence to be a fundamental characteristic of the perceptual experience.

The standard view offers an unfortunate way of pinning down what naive realism amounts to. It portrays the naive realist as being committed to a controversial theory about perceptual experience-relationalism-where there is no such commitment. People have assumed that conceiving of perceptual experience as fundamentally presentational somehow commits you to conceiving of perceptual experience as fundamentally relational. But this is false. My aim in this paper is to clear up this confusion and argue that a naive realist need not be a relationalist.

My conclusion changes how we should understand naive realism and promises to reshape the wider debate about perceptual experience. If a perceptual episode by its very nature involves a relation of awareness, then any perceptual experience is fundamentally both an object-dependent and a mind-dependent occurrence. Yet it is far from obvious that a naive realist must affirm that perceptual experiences are mind-dependent in this fundamental way. My argument will show that a naive realist can safeguard a deeply realist view of perception according to which neither the objects of perception nor the episodes in which those objects present themselves to us depend on the mind. This view is worth defending in its own right, yet we lose sight of this thoroughly realist outlook if we do not clearly distinguish between naive realism and the relational view of perception.

\footnotetext{
i I will follow convention and assume that experiences are episodes or events. My argument does not require this assumption, and what I will say in this paper can be reformulated in terms of (mental) states or attitudes.
} 
Here is a plan of the paper. I argue first (\$2) that the relationalist thesis is logically independent of the basic naive realist assumption that perception is fundamentally presentational. This implies that the claim that naive realism entails relationalism requires additional presuppositions. In $\S 3$ I argue that the only plausible additional presupposition - that a perceptual relation would account for the distinctive phenomenal character of perceptual experience-is controversial. More to the point, there is an argument against relationalism about perception that can be entirely endorsed by the naive realist. The argument is the converse of the familiar argument from hallucination, which I discuss in $\$ 4$. What is significant about hallucinations is that they are episodes that are not object-dependent, yet can plausibly be taken to belong to the same fundamental kind as perceptual experiences. In \$5 I suggest that we can identify another kind of episode, events of appearing, which conversely are not mind-dependent and which can also plausibly be taken to belong to the same fundamental kind as perceptual experiences. Taking seriously this basic connection between perceptual experiences and the broader class of events of appearing, in §6 I provide an argument-a structural converse of the argument from hallucinationthat shows that perceptual experiences belong to a fundamental kind of event that is not minddependent. This 'argument from appearing' undermines relationalism, yet it leaves naive realism untouched. This suffices to show that naive realism about perception neither entails nor commits one to relationalism.

\section{Naive realism and the relational assumption}

It is uncontroversial that at the heart of naive realism lies a conception of perceptual experience as a kind of phenomenal episode that is fundamentally presentational. A phenomenal episode is presentational if and only if the episode is constituted at least in part by some mind-independent objects and their qualities, such that those objects and qualities determine the phenomenal character of the episode. The term 'presentational' is here used technically, and the previous definition is more specific than simply the idea that the object of experience must be present, i.e. in a particular place; the episode also must be constituted by the object in a way that determines phenomenal character. As Matthew Soteriou puts it:

According to naïve realism, when one veridically perceives the world, the mindindependent items perceived, such as tables and trees and the properties they manifest to one when perceived, partly constitute one's conscious experience, and hence determine its phenomenal character. $(2016$, p. 221)

The idea behind this conception of experience is that your current perceptual experience has its phenomenal character - the ground of what it is like to have the experience - at least in part because the objects you become aware of have that character (where the 'because' introduces a constitutive explanation, not a causal one). This makes it that the episode is object-dependent.

For example, assuming that you are currently reading some words printed on a screen or a page, it is the mind-independent character of the printed words before you that constitutes part of the phenomenal character of the experience. In other words, at least some facts about what it is like for you to undergo the episode are facts about ordinary, mind-independent objects and their manifest properties. It is in this way that a mind-independent environment can be said simply to show up to you in perceptual experience.

To claim that an event or episode $x$ is fundamentally presentational is to claim that no event or episode $y$ of the same most specific kind to which $x$ belongs could occur without $y$ being presentational (for this use of 'fundamental', see Soteriou 2016, p. 199; Logue 2013, p. 108; Martin 2006; Wiggins 1980, 2001). The naive realist assumes that to characterize our perceptual experiences in a way that reflects their nature, or what is most fundamentally true of them, we have to say that they are presentations of items and qualities that exist mind-independently in the environment (see also Martin 2006, p. 354; Campbell 2002, p. 116). Proponents of naive realism 
about perceptual experience argue that only this conception of perceptual experience captures the 'naive' or common-sense idea, implicit in our everyday talk and behaviour, that perception is simply a way for the mind-independent world to show up to us. Charles Travis writes that a defence of this common sense idea already figured in the work of J.L. Austin, who thought that "rather than representing anything as so, our senses merely bring our surroundings into view; afford us some sort of awareness of them." (Travis 2004, p. 64; see also Martin 2006). The naive realist follows Austin and conceives of the perceptual experience as simply the visual, tactile or otherwise sensible presentation of an environment that would have been there to perceive anyway.

The idea that perceptual experiences are fundamentally presentational lies at the heart of naive realism: one cannot be a naive realist and deny it. But conceiving of perceptual experience as a kind of phenomenal episode that is fundamentally presentational is also sufficient for a naive realist conception of perceptual experience (Martin 2006; Nudds 2009, p. 335; Berger and Nanay 2016, p. 426). In other words, you count as a naive realist as soon as you hold that perceptual experiences are by their very nature constituted at least in part by the mind-independent objects and their qualities, such that those objects and qualities determine the phenomenal character of the episode.

Most sympathizers and critics of naive realism already accept these points. However, they typically also assume that this commitment about the fundamental nature of perceptual experience commits naive realists to a 'relational assumption'. Soteriou characterizes this relational assumption as follows:

According to those who advocate this view, when you have a conscious perceptual experience it seems, from the inside, as though you are perceptually aware of various entities, and this is to be explained by the fact that when you have a conscious perceptual experience you are perceptually aware of various entities. A distinctive kind of conscious, perceptual relation obtains between you, as subject of the experience, and various entities that you are perceptually aware of in having that experience. (2016, p. 7)

The relational assumption implies that perceptual experiences by their very nature involve a distinctive, conscious relation between a subject of experience and the mind-independent world. In other words, someone who makes the assumption ('a relationalist') will maintain that no event or episode of the same fundamental kind as your current perceptual experience could occur in the absence of a perceptual relation between a mind and some object or quality. The relational assumption implies that perceptual experiences are fundamentally both mind-dependent and objectdependent.

It is not at all obvious that a naive realist is indeed committed to relationalism in this sense. Still, many authors explicitly maintain that a naive realist is committed to the relational assumption. Heather Logue, for example, writes that naive realism holds that "at least some perceptual experiences fundamentally consist in the subject bearing the perceptual relation to something" (2014, p. 225). Craig French writes that naive realists hold that "perceptual experiences have a relational nature such that, in a perceptual experience, a perceiving subject stands in a perceptual relation to mind-independent objects" (French 2018). Some even go so far as to identify the two positions. For example, Tyler Burge takes naive realism to be "roughly the view that veridical perception is, without residue, a relation between a perceiver and an object" (2005, p. 2). And Bill Fish writes that "As theories of the conscious character of visual experience, I take naive realism and relationalism to be alternative names for the same thesis" (2009, p. 3n; see also Nanay 2014 and Beck 2019).

It should be clear, however, that a relationalism about perception is not itself sufficient for a naive realist conception of perceptual experience. As Laura Gow has pointed out, some forms of representationalism about perception are relationalist as well (Gow 2018). Moreover, a sense-datum theorist can also endorse the relational assumption without thinking that one's perceptual 
experience is by its very nature constituted (at least in part) by mind-independent objects and qualities. Instead, they may assume it is constituted by mind-dependent sense-data (Robinson 1994). For these reasons, relationalism does not entail naive realism. The more interesting question to consider, however, is whether it is necessary for a naive realist to be a relationalist.

First of all, if it is true that naive realism entails relationalism, then this does not seem to be a logical truth. The claim that perceptual experience is a kind of episode or event that is by its very nature presentational, and the claim that perceptual experience is a kind of episode or event that is by its very nature relational, are not obviously logically equivalent. By analogy, consider the following claims:

A. By its very nature your outfit is at least in part constituted by some garments, such that those garments determine what it is like to wear the outfit

B. By its very nature your outfit involves a relation between you and some garments

Clearly, claim A is true. Because it is a collection of clothes, your outfit is constituted by the garments that make it up. Moreover, the garments that constitute the outfit also determine, at least in part, its character and feel. However, as a collection of clothes, your outfit could equally have been worn by someone else or by nobody at all. We do not normally think of a collection of clothes, or its distinctive feel, as essentially belonging to any person, let alone the person who happens to be wearing it. Therefore claim B is false. This illustrates that simply from the assumption that $x$ is by its very nature constituted by $y$, such that $y$ determines $x$ 's character, it doesn't follow that $x$ by its very nature involves a relation to some $z$ distinct from $y$. This suggests that the claim that a perceptual experience is a kind of episode or event that is by its very nature presentational does not logically entail the claim that a perceptual experience is a kind of episode or event that is by its very nature relational.

If the claim that a perceptual experience is a kind of episode or event that is by its very nature presentational does not logically entail the claim that a perceptual experience is a kind of episode or event that is by its very nature relational, then it does not follow that a perceptual experience, when conceived as a fundamentally presentational episode, must thereby be conceived as a kind of episode that fundamentally involves a perceptual relation. In that case, if relationalism somehow is a necessary commitment of any naive realist, then this could only be because of some further fact. In the next section I consider the most plausible candidate.

\section{Explaining phenomenal character}

Why would anyone think that naive realism must ultimately take the form of a relationalism about perceptual experience? One readily available answer has to do with the distinctive phenomenology of perceptual experience: perhaps only a relation between a subject and the mind-independent objects or properties perceived can ground or explain (at least in part) the distinctive phenomenal character of perceptual experience in a way that respects naive realism.

Many authors who have written about the nature of perception agree that perceptual experience possesses a seeming 'transparency' or 'openness' to the world (Martin 2002; Crane and French 2017). This means that, from a subject's point of view, perceptual experiences seem to be simple presentations of items and qualities in the environment and seem to allow one to learn about those very items or qualities. The Austinian characterisation of perception as simply bringing our surroundings into view is meant to capture this distinctive phenomenal character. As M.G.F. Martin puts it, "in its very conscious and so subjective character, the experience seems literally to include the world" (1997, p. 84).

But how could an experience have such a distinctive character? One might argue that a relation of acquaintance or awareness could help a naive realist answer this question. James Genone suggests that this indeed motivates naive realists to endorse relationalism: "In claiming that relations of awareness to objects and properties are part of the fundamental metaphysical nature of 
perceptual experience," he writes, "naïve realists hold that such relations are sufficient to account for the main explanatory challenges facing a theory of perception, in particular the phenomenology and epistemic role of experience" (2016). The thought here is that a naive realist is able to explain, at least in part, why your perceptual experience has this seeming transparency to the world, by referring to the fact that the experience relates you, as a conscious subject, to the mind-independent objects in your environment (see also Soteriou 2016, p. 40).

Concerns about answering an explanatory challenge may seem compelling. However, they offer no ground for attributing a relationalist assumption to the naive realist. The assumption that a relation of awareness explains the seeming transparency of perceptual experience goes well beyond anything a naive realist needs to claim. First, that one's perceptual experience is by its very nature constituted at least in part by the mind-independent objects and their qualities, such that those objects and qualities determine the phenomenal character of the episode, at best entails that at least some facts about the character of your perceptual experience are facts about ordinary, mindindependent objects and their manifest properties. This in turn suggests that some of the phenomenal character of the experience you have turns out to be identical to the character of some mind-independent things. Many naive realists indeed accept such an identity (e.g. Martin 1997; Kalderon 2007, p. 598). Nonetheless, it should be clear that accepting an identity between facts about objects and facts about experience does not itself commit you to any one specific explanation of that identity. Relationalism might be one way of explaining why perceptual experience has the phenomenal character it does, but it is certainly not the only way.

Moreover, suppose that the relational assumption offered the only possible explanation of the distinctive phenomenal character of perceptual experience as the naive realist conceives of it (which itself is unlikely).ii Then still a naive realist would be free to deny that the phenomenal character of perceptual experience demands an explanation to begin with. Primitivism about the character of perceptual experience is available, also to the naive realist (pace Tye 2015, p. 319). That perceptual experiences seem, from a subject's point of view, to be simple presentations of items and qualities in an environment may just be a basic fact about the fundamental kind of event or episode that a perceptual experience is.

If the transparency of experience is a basic fact, it would be misguided even to think that there is an explanatory challenge. Acknowledging that perceptual experience indeed possesses this seeming 'transparency' or 'openness' to the world, a naive realist could urge that this is just what it is for items and sensible qualities in our environment to come into view (see e.g. Johnston 2009, Ch. 9 for a suggestion along these lines). Accepting the transparency of perceptual experience does not itself commit one to accepting the relational assumption. Hence, the claim that a naive realist must accept relationalism to explain the seeming transparency of perceptual experience is therefore baseless.

There could of course be other facts that make it seem that naive realism is ultimately defensible only as a relationalism about perceptual experience. So far I have not found any plausible candidate. But I can demonstrate that naive realism and relationalism can come apart, by showing that naive realism can be maintained even if relationalism is false. I will do this in the remainder of this paper. My starting point is the familiar argument from hallucination. I will develop an argument against relationalism that is structurally analogous to the argument from hallucination. I call it the argument from appearing. The argument from appearing undermines relationalism, but, in contrast to the argument from hallucination, each of its premises can be accepted by a naive realist. The validity of this argument suffices to demonstrate that naive realists need not be relationalists.

\footnotetext{
ii It is unlikely that the relational assumption offers the only possible explanation of the distinctive phenomenal character of perceptual experience as the naive realist conceives of it, because many versions of representationalism eschew relationalism and yet take themselves to be well placed to explain why your perceptual experience has the distinctive phenomenal character it has. See e.g. Harman 1990 and Siegel 2010.
} 


\section{Lessons of hallucination}

A relation obtains only if all of its relata-the things that stand in the relation-exist. Accordingly, the standard argument against the relational assumption purports to show that for at least some events that belong to the fundamental kind of phenomenal episode to which also your current perceptual experience belongs, one or more of the alleged perceptual relata need not exist. This would prove that perceptual experiences do not by their very nature relate conscious subjects to mind-independent objects in their environment.

Without exception, the traditional arguments against the relational assumption focus on the non-existence of the object of experience. The argument from hallucination does just this. Suppose that Paula, a normal perceiver, has a vivid hallucination of seeing a dagger at some distance from her. When we know that Paula hallucinates a dagger, we do not have to suppose that there now also exists a dagger she is related to. Hallucinations do not entail the existence of the objects hallucinated; they are not object-dependent. But now consider that some possible episodes of hallucination are indistinguishable, at least subjectively, from a normal perception of a dagger. This may suggest that hallucinations belong to the same fundamental kind of phenomenal episode as standard perceptual experiences. And if they do, then the possibility of such hallucinations proves that perceptual experiences are not by their very nature object-dependent, and so do not by their very nature involve a relation between a subject of experience and some object of experience. The relational assumption would be false.

Though controversial, the argument from hallucination is widely accepted. Most philosophers who currently accept the argument from hallucination take it to show that perceptual experiences, just as hallucinations, are fundamentally representational episodes. By this they mean at least that one's perceptual experience is a phenomenal episode or event that is not by its very nature constituted by the objects one perceives (e.g. Harman 1990; Siegel 2010; Nanay 2014). iii Such phenomenal episodes are, in the good or veridical case, appropriately linked to actual, mindindependent objects in one's environment (e.g. by being caused by those objects). Where such a link is present, the episode can veridically represent how one's environment actually is. We then speak of a perception or perceptual experience. On the other hand, in cases where such an appropriate link is absent, we have a non-veridical experience, such as an illusion, imagining or hallucination. Such non-veridical experiences do not veridically represent how one's environment actually is, unless they do so by lucky accident (Lewis 1980).

Note, the need for a suitably linked object for a perceptual experience to occur does not force us to think of the perceptual experience as fundamentally a different kind of phenomenon than a hallucination (where there is no such need). Indeed, because they reject the idea that perception is fundamentally object-dependent, the representationalist can conceive of episodes of experience in a way that leaves it to extrinsic factors to determine whether we are dealing with a perception, or some kind of non-veridical experience, such as a hallucination.iv This would imply that the proper analysis of the notion of perceptual experience is conjunctive: a perceptual experience is fundamentally a representational episode, but one that happens to be appropriately linked to an actual object in the environment (Johnston 2004, p. 114). You may correctly introspect that you have a visual experience of a dagger, but this does not yet give you a conclusive reason to think that there exists a dagger you experience, because introspection might still be insufficient to determine whether the appropriate link to any actual dagger is also secured.

\footnotetext{
iii An alternative take on the argument from hallucination is to suggest that the possibility of hallucination shows that the objects of perceptual experience are available even to someone in a hallucinatory state; see Robinson 1994 and Johnston 2004 for different ways of elaborating this suggestion.

iv See Hinton 1969 for a critical discussion of the notion of experience that is at work in the representationalist argument. See Byrne 2009 for a critical response.
} 
If the representationalist is right, then perceptual experiences do not fundamentally differ from hallucinations, and so perceptual experiences do not fundamentally involve a perceptual relation. ${ }^{v}$ We should also note that the argument from hallucination, if sound, not only undermines the idea that perceptual experiences by their very nature involve a perceptual relation; the argument also undermines the idea that perceptual experiences by their very nature are constituted at least in part by the mind-independent objects and their qualities, such that those objects and qualities determine the phenomenal character of the episode. This is because, just as a relation presupposes the existence of its relata, instances of constitution presuppose the existence of their constituents. And the items the naive realist takes to be constituents of the experience are precisely what the relationalist regards as belonging to the perception's relata that are taken to be missing when we undergo a hallucination: the mind-independent objects and their qualities. In other words, the argument from hallucination threatens both the relational assumption, and the assumption that perceptual experiences are fundamentally presentational (Nudds 2009, p. 335). vi

The argument from hallucination is not conclusive. The main weakness of the argument is well known: it asks us to draw conclusions about ordinary perception from observations about hallucination, a kind of phenomenal episode that is not obviously of the same fundamental kind as a perceptual experience. Everyone agrees that there is some difference between hallucinations and veridical perceptions, and so it may well be that they turn out to be fundamentally different phenomena (Martin 2006). Moreover, it is clear that hallucinations in some sense fall short or depart from the norm - they are 'non-veridical' experiences, if they are experiences at all. The argument from hallucination requires us to assume that, despite their obvious abnormality, hallucinations, as non-relational phenomena, exemplify the same fundamental kind of episode as standard perceptual experiences. This is what M.G.F. Martin has called a Common Kind Assumption, "that whatever kind of mental, or more narrowly experiential, event occurs when one perceives, the very same kind of event could occur were one hallucinating" (Martin 2006, p. 357). It suggests that the philosopher interested in the fundamental nature of perception can at least in principle come to know all they want to know by finding things out about hallucination, given that (according to the Common Kind Assumption) hallucinations manifest the same fundamental nature.

We can now see that the conclusion of the argument from hallucination rests on two premises (cf. Crane and French 2017):

1. Hallucinations by their very nature do not involve a relation between a subject of experience and an object of experience

2. For any perceptual experience you have, the very same kind of event could occur were a hallucination to occur

3. Therefore, perceptual experiences by their very nature do not involve a relation between a subject of experience and an object of experience

It is perhaps unsurprising that typical responses to the argument from hallucination resist the second premise, the Common Kind Assumption, as it is the most controversial of the premises. Authors who have wished to defend relationalist or naive realist understandings of perception have almost invariably denied that hallucinations belong to the same fundamental kind as perceptual experiences, despite their superficial similarities (Martin 2006; Soteriou 2016; see Johnston 2004

\footnotetext{
v Johnston 2004 offers the resources to defend the idea that also hallucinations are fundamentally relational, though he does not explicitly argue for this point. I will set this relational view of hallucinations aside, but see Raleigh 2014 for discussion. It is widely accepted that hallucinations are non-relational phenomena.

vi As Gow (2018) brings out, the argument from hallucination also threatens relationalism as such. This includes versions of relationalism that do not commit to a naive realism.
} 
for an exception). Here I do not need to settle the dispute about whether the Common Kind Assumption is ultimately defensible. What matters for my purposes is that the argument from hallucination offers a template of how to argue successfully against the relational assumption: Try to show that one of the alleged relata in the alleged perceptual relation involved in a perceptual experience need not exist for an episode of the same fundamental kind to occur. As a corollary, one can show that a naive realist is not committed to relationalism by showing that this rejection of the relational assumption is acceptable in principle to a naive realist. For it would mean that at least some versions of naive realism are not committed to the relational assumption, because they can positively reject it. And if a naive realist can positively reject relationalism, then the two positions cannot but be strictly distinct.

But is there such a way? Can one undermine the relational assumption while leaving naive realism untouched? Clearly, both the relationalist and the naive realist are committed to the existence of the mind-independent objects and qualities that are presented in an experience. Yet there is good indication to think that a relationalist is committed to more. On the relational assumption, whenever we perceive a tomato, an episode of that same fundamental kind could not occur in the absence of either the object or the subject of experience (as well as the relation between the two). The perceptual relation requires both object and subject. By contrast, it is not at all obvious that the naive realist has this double commitment. For sure, a naive realist accepts that any perceptual experience is object-dependent, for this is presupposed by the assumption that perceptions are fundamentally presentational. But must they equally assume that all perception is subject-dependent? Not if there are episodes which, while lacking a subject of experience, on a naive realist picture would still belong to the same fundamental kind as perceptual experiences. Are there such episodes? In what follows I will argue that there are.

\section{Mind-independent appearings}

How could episodes of the very same kind as perceptual experiences occur in the absence of a subject of experience? Aren't perceptual experiences fundamentally mind-dependent episodes? A motivation for rejecting such an assumption can be found in Russell's The Analysis of Mind (1921).

Russell denies that a subject or mind plays any substantive role in the analysis of mental phenomena, including perception. Russell follows his contemporaries in distinguishing conceptually between the object of experience, the mental content of experience, and the mental act of experience itself $(1921$, p. 16). He insists that in reality perception is not constituted by any contents or acts at all. Where most philosophers hold that perception must be analyzed as some possible compound of the three ingredients of act, content and object, Russell rails against such a view. He dismisses the appeal to perceptual act and perceptual contents - phenomena that require a mind for their reality -in standard theories of perception as 'ghosts of the subject' (p. 18). In the analysis of perception, he maintains, we can do away with both mental contents and mental acts and leave only the object and its qualities to account for what perception is. vii

What is the positive view defended here? To be sure, The Analysis of Mind contains a far more complex position on mental life, one that ties together metaphysical, epistemological and scientific considerations. But the heart of its theory of perception is the simple idea that perceptions are appearances of objects. When you have a perception, a mind-independent reality appears to you. Your perceptual experience is no more than a kind of appearance of an object: an appearance that happens to occur in the presence of an organism with some degree of consciousness. As Russell puts it:

\footnotetext{
vii Russell here takes inspiration from John Dewey, who suggests that a realist "try the experiment of conceiving perceptions as pure natural events, not as cases of awareness or apprehension, and they will be surprised to see how little they miss" (1916, p. 262).
} 
we may define a "perception" of an object as the appearance of the object from a place where there is a brain (or, in lower animals, some suitable nervous structure), with senseorgans and nerves forming part of the intervening medium. (1921, p. 181; see also p. 104ff)

As conscious organisms with suitable sensory apparatuses, Russell assumes, human beings are receptive to appearances of objects in their environment. A perceptual experience is simply the appearance of such an object where this appearance is registered by some organism.

Note that the 'appearance' of an object here is to be understood as referring to a kind of occurrence in which some object takes part, not as referring to the object itself or a quality of the object. An appearance requires some sensible object or quality to appear-it is the event or episode of the object's appearing in some situation (cf. Cook-Wilson 1926, 796-797; Price 1964; Alston 1999). Think of how a parakeet can be said to have appeared on my lawn on a Wednesday afternoon. The bird was a participant in that occurrence-the appearance couldn't have taken place without it. By their very nature, appearances are possibly sensed. ${ }^{\text {vii }}$ The appearing of the parakeet was an event that could have been registered by a suitably placed sensory apparatus. For this reason appearances are phenomenal episodes or events.

One implication of this concept of appearances as events of appearing is that they can take place regardless of whether there is anyone around actually to register the appearance when it takes place. At least on a realist assumption this is unobjectionable. A parakeet can appear in a garden regardless of whether there actually is anyone to appreciate its visual presence. When rays of light diffusely reflecting off its wings reach the other side of the lawn, the bird becomes visible from that side: as soon as the reflected light has spread, the bird appears, visually, at the far end of the garden. The bird is sensibly present in this way, regardless of whether there is someone around actually to become aware of its presence. It appears in (or to) some region of space, but not necessarily to anyone or anything occupying some point in that region (see also Johnston 2007, p. 260). In particular, the bird's appearance does not require the presence of a subject. As Russell illustrates, a photographic plate placed on one end of the garden would equally be able to register the bird's appearance by forming an image of the animal and its visual qualities (1921, p. 99). Photography gives evidence of the appearance's mind-independent occurrence.

This straightforwardly realist conception of appearances, according to which objects and properties appear how they do regardless of whether they are perceptually experienced, is very much in line with a naive realism about perceptual experience. ${ }^{\text {ix }}$ Recall the Austinian idea that, rather than being represented, when we have a perceptual experience our surroundings simply come into view. The naive realist, by accepting that perceptual experiences are fundamentally presentational, already assumes that the items and qualities manifest to you when a bird appears to you do not depend on the existence of either a subject of experience or a perceiving organism, or anything apart from the bird and the way it presents itself (Campbell 2002; Martin 1997). A natural corollary of this is that the presentation of the bird is itself not fundamentally mind-dependent.

\footnotetext{
viii That appearances are by their very nature possibly sensed does not mean that an account of appearances must take as metaphysically prior what it is to sense or perceive the thing that appears. At least on a realist assumption, it is not objectionable as such to assume that the sensible character of the appearance is grounded in some primitive mind-independent feature (Campbell 2002; Martin 1997). Hence, although it is true that if someone were suitably positioned they would sense or perceive the parakeet landing in the garden, this counterfactual need not be taken to reveal the nature of the appearance as such.
}

ix To be clear, Russell still ends up endorsing a specific form of sense datum theory of perception. Yet, a naive realist can easily accept Russell's non-relational way of thinking about perceptual experience without endorsing the further assumptions that lead to a sense-datum theory. This is because naive realism and sense datum theory are structurally similar, and disagree only about the nature of the objects of experience or whether these objects are fully revealed - 'given' - in the experience or not (Logue 2014, p. 225). 
Moreover, this conception of perceptual experiences still allows them to be fundamentally presentational. The appearance of the parakeet on my lawn ontologically depends on that very parakeet and its qualities (as well as on the lawn, its qualities, and any other participants in the event), simply because the bird is a constitutive participant in the event; it could not have been the appearance of that very parakeet if some other bird had turned up. Moreover, that very parakeet and its qualities determine the sensible character of the episode: that the appearance is the appearance of something greenish and not something blueish is because the parakeet is greenish, and not blueish. Accordingly, the episode of the parakeet's appearing on the lawn is constituted at least in part by some mind-independent object and its qualities, such that this object and its qualities determine the phenomenal character of the episode and accordingly determine what it is like for a conscious organism to undergo the episode. Similarly, the character of a photographic image registered by the plate on the far side of the garden would be determined in part by those objects and qualities that constitute the appearance the plate is designed to register.

To be clear, that objects and their qualities can appear quite independently of any perceiver does of course not imply that perceptual experiences can occur in the absence of a perceiver. For Russell, this is ruled out by the conjunctive analysis of perceptual experience that his account suggests. Perceptual experiences are complex events, in which on the one hand some mindindependent item appears in a certain way, while on the other some organism with a brain, sensory organs and nerves registers this appearance. Only when both of these conditions - an appearance as well as its registration by an organism - are satisfied is the appearance of the item in question a perceptual experience. When no one is around to register the appearance, we can speak of a 'mere appearance'; it is a presentation of an object in circumstances where a conscious subject is absent. However, none of this makes the event of appearing that is the perception - the phenomenal episode or event in which objects and qualities manifest themselves - in any way mind-dependent (a similar point is made by Johnston 2007).

What results is a boldly realist take on perceptual experience. Although the occurrence of those appearances that amount to perceptual experiences presupposes some psychological occurrences-such as the formation of mnemic traces in some organism or brain-such psychological occurrences never constitute the event in which something sensibly appears as such, not even in part. Perceptual experiences are appearances that happen to possess an additional feature: they occur in the presence of a suitably placed sensitive organism. Hence, someone who adopts this analysis of perceptual experience can accept that an appearance that occurs in the absence of a subject of experience can belong to the same fundamental kind as your current perceptual experience. This would mean that perceptual experiences are not by their very nature mind-dependent events. This analysis of perceptual experience is not only compatible with, but naturally complements, the naive realist claim that a perceptual experience is by its very nature constituted at least in part by mind-independent items and their qualities, such that they determine the phenomenal character of the episode. Hence, it is possible to accept a boldly realist view of perception as an event of a fundamental kind that is not mind-dependent as part of a naive realism about perceptual experience.

\section{The argument from appearing}

If one accepts that a perceptual experience by its nature is no more than an appearance of a mindindependent object and its qualities (be it in the presence of a suitably placed organism), then one can accept that an episode of this same fundamental kind can occur also in the absence of a perceiver or subject of experience. The previous discussion has shown this to be correct. This analysis prepares the ground for an argument against relationalism that is the exact converse of the argument from hallucination. Call this the 'argument from appearing'.

The argument rests on two premises: 
1. Mere appearances by their very nature do not involve a relation between a subject of experience and an object of experience

2. For any perceptual experience you have, the very same kind of event could occur were a mere appearance to occur

3. Therefore, perceptual experiences by their very nature do not involve a relation between a subject of experience and an object of experience

Consider a tree in a park, on a Wednesday afternoon, with no one around to perceive it. That tree, illuminated by the midday sun and coloured and shaped as it is, appears in the park, both visually and tactually. There occurs a phenomenal episode in which the tree and its qualities manifest themselves. To assume that the tree appears in the park in this way does not require assuming that there now also exists some perceiver or subject of experience that the tree is related to. ${ }^{\mathrm{x}}$ Mere appearances do not entail the existence of any minds. But now consider that such an appearance is just what you would experience if you were there to perceive the tree. Surely, the mere fact that some appearance is now registered by you does not make any difference to the appearance as such. Hence a tree's appearing to nobody and a tree's appearing to somebody are not events of a different fundamental kind. Standard perceptual experiences can belong to the same fundamental kind of phenomenal episode as mere appearances. If this is right, then perceptual experiences are events that are not by their very nature mind-dependent. And if so, then given that any relation between a subject and an object of experience requires there to be a subject, perceptual experiences cannot by their very nature involve a relation between a subject of experience and some object of experience. If perceptual experiences indeed belong to the same fundamental kind as mere appearances, then the relational assumption is false.

Notice that the argument from appearing is identical in form to the argument from hallucination. Recall:

1. Hallucinations by their very nature do not involve a relation between a subject of experience and an object of experience

2. For any perceptual experience you have, the very same kind of event could occur were a hallucination to occur

3. Therefore, perceptual experiences by their very nature do not involve a relation between a subject of experience and an object of experience

Both of the arguments bring out that although it may be true that we cannot have a perception without the existence of the relata of the perceptual relation, this does not mean that perception is the kind of event that fundamentally requires the existence of these relata. This is because an episode of the same fundamental kind can occur even when some of the relata do not exist. The arguments' conclusions are identical too: perceptual experiences do not by their nature involve a relation between a subject of experience and an object of experience. The arguments differ only in which non-perceptual episode they take as their focus. The argument from hallucination uses the possibility of hallucinations to show that a relation is not fundamental to perception, while the argument from appearing uses the possibility of mere appearances to

\footnotetext{
$\mathrm{x}$ Note, I am not here assuming that we can imagine a tree unperceived. All that my argument requires is that we can make sense of the possibility of an unperceived tree, which I take to be unproblematic even on a moderate perceptual realism.
} 
demonstrate the same conclusion. ${ }^{x i}$ This is where the arguments are each other's converse, as they focus on opposing ends of the alleged perceptual relation - in the one case the dispensability of an object of experience, in the other the dispensability of a subject of experience.

If sound, both the argument from hallucination and the argument from appearing undermine relationalism about perceptual experience. However, there is a crucial difference between the two arguments. In addition to undermining relationalism, the argument from hallucination also threatens naive realism about perception. Hence, naive realists can universally be found to resist the argument from hallucination. Superficially this may give the impression that, in resisting the argument from hallucination, naive realists would be seeking to salvage relationalism-hence easily inviting the association of the two positions (naive realism and relationalism) so common in current scholarship.

That no such association between naive realism and relationalism is warranted becomes clear when considering the results of the argument from appearing. Like the argument from hallucination, the argument from appearing would undermine relationalism about perceptual experience. Yet, in contrast with the argument from hallucination, it poses no threat whatsoever to naive realism. A naive realist can easily accept both of its premises - that mere appearances are not fundamentally mind-dependent, and that the fundamental kind to which perceptual experiences belong can be shared with mere appearances - as well as its conclusion.

In a way, the naive realist position with respect to the relational assumption resembles that of the representationalist. Recall, a representationalist may accept the Common Kind Assumption, and urge that the term 'veridical perception' merely serves to register the fact that in certain cases we are dealing with a complex situation that involves, besides a kind of representational episode, an appropriate tie to an actual object in the environment. Similarly, a naive realist may make a similar assumption, and take the term 'perceptual experience' merely to register the fact that we are dealing with a complex situation that involves not just the sensible appearance of some object, but also a some conscious being that registers that appearance. Making the latter assumption is perfectly compatible with the idea that a perceptual experience is by its very nature constituted at least in part by some mind-independent object and its qualities, such that those determine the phenomenal character of the episode. Accepting that perceptual experiences fundamentally are no more than sensible appearances of mind-independent objects is consistent with thinking of perceptual experiences as fundamentally presentational.

This implies that a naive realist can accept both premises and the conclusion of the argument from appearing. When you have a perceptual experience of a parakeet, the event of which you are or seem to be the subject does not by its very nature involve a relation between the bird and some subject of experience. Hence, a naive realist can accept that the relational assumption is false.

This conclusion brings out a key contrast between naive realism and relationalism. Relationalists about perception, by requiring there to be a subject of experience as one of the two relata of the perceptual relation, must conceive of perceptual experiences as by their very nature mind-dependent events. No such thing is true of a naive realist. What any naive realist must affirm is only that the perceptual experience, by its very nature, depends on some mind-independent object and its qualities. They need not accept that perceptual experiences at the same time by their very nature entail the existence of some mind. In this way, naive realism embodies a deeply realist view of both the objects of perception and of the phenomenal episodes in which those objects present themselves to us. This kind of realist treatment of perceptual experience gets obscured if we assume that naive realism is committed to a relational view of perception.

\footnotetext{
xi A consequence of this difference in focus is that the Russellian argument avoids relying on taking obviously defective cases to exemplify the fundamental nature of perceptual experience: though there is obviously something wrong with an experience of a tree in the absence of a tree, there is not obviously something wrong with the appearance of the tree in the absence of a perceiver. If anything, it seems the more common phenomenon, at least if we are not Berkelean idealists.
} 


\section{Conclusion}

A relationalist about perception maintains that perceptual experience by its very nature involves a distinctive kind of conscious perceptual relation between a subject and some mind-independent reality. Naive realism is compatible with a relationalism. But even though naive realism could be combined with some form of relationalism, I have shown that this is by no means mandatory. Contrary to what is commonly assumed in current scholarship, naive realism is neither logically equivalent to nor entails any form of relationalism. One can be a naive realist without being a relationalist.

To establish this, I have presented three arguments. First, I argued that from the assumption that perceptual experiences are by their very nature presentational it does not seem to follow logically that they must involve a distinctive conscious perceptual relation to a subject of experience. Second, I argued that a relationalism is not required to account for the phenomenal character of perceptual experience. Third, I have constructed an argument against relationalism about perceptual experience that can be accepted by a naive realist. This is the argument from appearing. The argument from appearing concludes that perceptual experiences are events of a kind that is not fundamentally mind-dependent. I have shown how this argument undermines relationalism, while the naive realist can accept both of its premises and its conclusion.

This is not simply a bookkeeping exercise for naive realists. Because authors have not clearly distinguished between naive realism and relationalism, arguments presented with a view on defending the relationalist position may turn out only to support naive realism. In such cases relationalism may prove itself unsupported. Moreover, if naive realism has fewer commitments than is standardly presumed, then some objections presented against the view may instead only undermine relationalism. The argument from appearing is a case in point. This may make naive realism more attractive as a philosophical view of perceptual experience compared to rival positions such as representationalism and sense-datum theory. Both these points deserve to be investigated in further work.

None of this is intended to show that any individual naive realist cannot coherently make additional relationalist assumptions. A perceptual realism can come in many strengths and guises. What I hope to have done here is to undermine the widespread conviction that the naive realist must take perceptual experience to be fundamentally a relational, mind-dependent phenomenon. ${ }^{\mathrm{ii}}$

\footnotetext{
xii I am grateful for discussion of this material to Roberta Locatelli, Susanna Schellenberg and Li Li Tan. I am also grateful to an anonymous referee for written comments.
} 


\section{References}

Alston, W. P. (1999). Back to the Theory of Appearing. Philosophical Perspectives, 13, 181-203

Beck, O. (2019). Rethinking naive realism. Philosophical Studies, 176, 607-633

Berger, J. and Nanay, B. (2016). Relationalism and Unconscious Perception. Analysis, 76, 426-433

Burge, T. (2005). Disjunctivism and Perceptual Psychology. Philosophical Topics, 33, 1-78

Byrne, A. (2009). Experience and Content. The Philosophical Quarterly, 59, 429-451

Campbell, J. (2002). Reference and Consciousness. Oxford: Oxford University Press.

Cook-Wilson, J. (1926). Statement and Inference. Oxford University Press, Oxford.

Crane, T. and French, C. (2017). The Problem of Perception, in Zalta, E. (ed.) The Stanford Encyclopedia of

Philosophy (Spring 2017), URL = <plato. stanford.edu/archives/spr2017/entries/perception-problem/>

Dewey, J. (1916). Essays in Experimental Logic. Chicago, Il: University of Chicago Press.

Fish, W. (2009). Perception, Hallucination, and Illusion. Oxford: Oxford University Press.

French, C. (2018). Naïve Realism and Diaphaneity. Proceedings of the Aristotelian Society, 118, 149-175

Genone, J. (2016). Recent work on Naive Realism. American Philosophical Quarterly, 53, 1-26

Gow, L. (2018). Why Externalist Representationalism is a Form of Disjunctivism. Ratio, 31, 35-50

Harman, G. (1990). The Intrinsic Quality of Experience, in Tomberlin, J. (ed.), Philosophical Perspectives, $4,31-52$

Hinton, J. M. (1973). Experiences. Oxford: Clarendon Press.

Johnston, M. (2004). The Obscure Object of Hallucination. Philosophical Studies, 120, 113-183

Johnston, M. (2007). Objective Mind and the Objectivity of Our Minds. Philosophy and Phenomenological

Research, 75, 233-268

Johnston, M. (2009). Saving God: Religion After Idolatry. Princeton: Princeton University Press.

Kalderon, M. (2007) Color illusion. The Philosophical Review, 116, 563-601.

Lewis, D. (1980). Veridical Hallucination and Prosthetic Vision. Australasian Journal of Philosophy, 58, 239-249

Logue, H. (2013). Good News for the Disjunctivist about (one of) the Bad Cases. Philosophy and Phenomenological Research, 86, 105-133

Logue, H. (2014). Experiential Content and Naive Realism: A Reconciliation, in Brogaard, B (ed.) Does Perception Have Content? New York: Oxford University Press.

Martin, M. G. F. (1997). The Reality of Appearances, in Sainsbury, M. (ed.) Thought and Ontology. Milan:

Franco Angeli.

Martin, M. G. F. (2002). The transparency of experience. Mind \& Language, 17, 376-425.

Martin, M.G.F. (2006). On Being Alienated, in Gendler, T. S. and Hawthorne, J. (eds.) Perceptual Experience. Oxford: Oxford University Press.

Nanay, B. (2014). The Representationalism versus Relationalism Debate: Explanatory Contextualism about Perception. European Journal of Philosophy, 23, 321-336

Nudds, M. (2009). Recent Work in Perception: Naive Realism and its Opponents. Analysis, 69, 334-346

Price, H. H. (1964). Appearing and Appearances. American Philosophical Quarterly, 1, 3-19

Russell, B. (1921). The Analysis of Mind. London: George Allen and Unwin.

Raleigh, T. (2014). A New Approach to 'Perfect' Hallucinations. Journal of Consciousness Studies, 21, 81109

Robinson, H. (1994) Perception. London: Routledge.

Siegel, S. (2010). Do Visual Experiences Have Contents? in Nanay, B. (ed.) Perceiving the World. Oxford: Oxford University Press.

Soteriou, M. (2016). Disjunctivism. London: Routledge.

Travis, C. (2004). The Silence of the Senses. Mind, 113, 57-94

Tye, M. (2015). The Nature of Pain and the Appearance/Reality Distinction, in Phenomenal Qualities: Sense, Perception, and Consciousness, Coates, P. and Coleman, S. (eds.) Oxford: Oxford University Press.

Wiggins, D. (1980). Sameness and Substance. Oxford: Basil Blackwell Ltd.

Wiggins, D. (2001). Sameness and Substance Renewed. Cambridge: Cambridge University Press. 